\title{
Millisecond Stimulus Onset-Asynchrony Enhances Information about Components in an Odor Mixture
}

\author{
Jacob S. Stierle, C. Giovanni Galizia, and Paul Szyszka \\ University of Konstanz, Department of Biology-Neurobiology, 78457 Konstanz, Germany
}

\begin{abstract}
Airborne odorants rarely occur as pure, isolated stimuli. In a natural environment, odorants that intermingle from multiple sources create mixtures in which the onset and offset of odor components are asynchronous. Odor mixtures are known to elicit interactions in both behavioral and physiological responses, changing the perceptive quality of mixtures compared with the components. However, relevant odors need to be segregated from a distractive background. Honeybees (Apis mellifera) can use stimulus onset asynchrony of as little as $6 \mathrm{~ms}$ to segregate learned odor components within a mixture. Using in vivo calcium imaging of projection neurons in the honeybee, we studied neuronal mechanisms of odor-background segregation based on stimulus onset asynchrony in the antennal lobe. We found that asynchronous mixtures elicit response patterns that are different from their synchronous counterpart: the responses to asynchronous mixtures contain more information about the constituent components. With longer onset shifts, more features of the components were present in the mixture response patterns. Moreover, we found that the processing of asynchronous mixtures activated more inhibitory interactions than the processing of synchronous mixtures. This study provides evidence of neuronal mechanisms that underlie odor-object segregation on a timescale much faster than found for mammals.
\end{abstract}

\section{Introduction}

Many tasks in an animal's life involve the detection of meaningful stimuli in a distractive environment. When stimuli occur together, object recognition requires grouping and segregation of stimuli. Sensory systems use stimulus asynchrony for segregation in vision (Usher and Donnelly, 1998; Hancock et al., 2008) and audition (Zera and Green, 1993; Bronkhorst, 2000; Lipp et al., 2010). It is unknown how the olfactory system segregates stimuli on the basis of asynchrony. The temporal relationship between components of a mixture contains information about the number of odor sources, potentially decisive for the ability to segregate the components from it (Stevenson and Wilson, 2007) and theoretically sufficient for a neural network to perform source separation (Hopfield, 1991). We therefore distinguish between two mixture qualities: odorants from the same source form mixtures with fixed concentration ratios and will be referred to as synchronous mixtures. Odorants from different sources mix in a complex way (Riffell et al., 2008) and comprise delays between components, changing concentration ratios, and will be referred to as asynchronous mixtures.

Synchronous mixtures often induce inhibitory mixture interactions in the principal neurons of the insect antennal lobe

\footnotetext{
Received Dec. 20, 2012; revised Feb. 18, 2013; accepted Feb. 22, 2013.

Author contributions: J.S.S., C.G.G., and P.S. designed research; J.S.S. and P.S. performed research; J.S.S. and P.S. analyzed data; J.S.S., C.G.G., and P.S. wrote the paper.

This work was supported by Bundesministerium für Bildung und Forschung (Grant \#01GQ0931 to P.S. and C.G.G.). We thank Martin Strauch for glomerulus mapping, Christoph Kleineidam for LabView programming, Tom Baker, Thomas Nowotny, Georg Raiser, and Anneke Meyer for fruitful discussions, and two anonymous reviewers for their valuable comments.

The authors declare no competing financial interests.

Correspondence should be addressed to Jacob S. Stierle, University of Konstanz, Department of Biology - Neurobiology, 78457 Konstanz, Germany. E-mail: jacob.stierle@uni-konstanz.de.

DOI:10.1523/JNEUROSCI.5838-12.2013

Copyright $\odot 2013$ the authors $\quad 0270-6474 / 13 / 336060-10 \$ 15.00 / 0$
}

(Joerges et al., 1997; Galizia et al., 2000; Deisig et al., 2006, 2010; Silbering and Galizia, 2007; Silbering et al., 2008; NajarRodriguez et al., 2010) or the vertebrate olfactory bulb (Tabor et al., 2004; Grossman et al., 2008). Inhibitory mixture interactions have been implicated with synthetic (or configural) odor processing, which leads to a loss of component information (Chandra and Smith, 1998; Smith, 1998; Deisig et al., 2002; Coureaud et al., 2009).

Perception and processing of asynchronous mixtures has been studied very little, and it is unknown how the brain uses millisecond stimulus asynchrony for odor-background segregation. Some studies suggest that processing of odor mixtures becomes more analytic (or elemental), which enhances information about the components when the components are applied asynchronously (Hopfield and Gelperin, 1989; Baker et al., 1998). Honeybees (Apis mellifera) can segregate components from a mixture better when they are presented with an offset of $6 \mathrm{~ms}$, producing an asynchronous mixture (Szyszka et al., 2012). In locusts, overlapping odor sequences evoke spatiotemporal patterns in the antennal lobe (AL) neurons that differ from both the single components and the synchronous mixture (Broome et al., 2006).

Using the same stimuli as Szyszka et al. (2012), we investigated neuronal responses to synchronous and asynchronous odor mixtures with calcium imaging of projection neurons (PNs) to answer the following questions: (1) are inhibitory mixture interactions dependent on the timing of the components?, and (2) do responses to asynchronous mixtures contain more information about the components than responses to synchronous mixtures? Our results show that PNs can resolve millisecond stimulus asynchrony and we conclude that olfactory object segregation is possible at the level of the AL. 
stimulus

\begin{tabular}{lll}
$A$ & $\begin{array}{l}\text { 1-hexanol } \\
\text { 1-nonanol }\end{array}$ & $\mathrm{N}$ \\
\hline $\mathrm{B}$ & $\begin{array}{l}\mathrm{H} \text { and N simultaneously } \\
=\text { synchronous mixture }\end{array}$ & $\mathrm{HN}$ \\
\hline $\mathrm{C}$ & $\mathrm{H} 200 \mathrm{~ms}$ before N & $\mathrm{H}-200-\mathrm{N}$ \\
& $\mathrm{H} 50 \mathrm{~ms}$ before N & $\mathrm{H}-50-\mathrm{N}$ \\
& $\mathrm{H} 6 \mathrm{~ms}$ before N & $\mathrm{H}-6-\mathrm{N}$ \\
& $\mathrm{N} 6 \mathrm{~ms}$ before $\mathrm{H}$ & $\mathrm{N}-6-\mathrm{H}$ \\
& $\mathrm{N} 50 \mathrm{~ms}$ before H & $\mathrm{N}-50-\mathrm{H}$ \\
& $\mathrm{N} 200 \mathrm{~ms}$ before $\mathrm{H}$ & $\mathrm{N}-200-\mathrm{H}$
\end{tabular}

Figure 1. Overview of the stimuli used in an experiment. Odorant pulses of $800 \mathrm{~ms}$ were given alone $(\boldsymbol{A})$, together $(\boldsymbol{B}$, synchronous mixture), or with a time delay between them $(\boldsymbol{C}$, asynchronous mixtures).

\section{Materials and Methods}

Animals. Free-flying honeybee foragers were used during the summer. During the winter, a hive was kept in a moistened and heated flight room with $12 \mathrm{~h}$ visible and UV light/ $12 \mathrm{~h}$ dark regime supplied with sucrose and pollen. Foragers (females) were caught at the hive entrance (summer bees) or from the ceiling of the flight room (winter bees), immobilized on ice, and mounted in custom-made acrylic glass stages with Deiberit adhesive wax (Dr. Böhme and Schöps).

Calcium imaging. Oregon Green-dextran ( Kd = $1180 \mathrm{~nm}, 10,000 \mathrm{MW}$; Invitrogen) was dissolved in a water droplet on a microscope slide to a viscous solution and applied to the tip of the glass needles, which were pulled on a horizontal puller (P-87; Sutter Instruments). Antennae were stuck to the forehead with Eicosane (Sigma-Aldrich). The head capsule was removed with a razor splint between compound eyes, antennae, and the medial ocellus. Glands and tracheae were removed from the mushroom body calyces. The dye was injected into the brain at the junction of the calyces of the mushroom body into the antenno-protocerebral tract that contains the axons of PNs, and allowed to travel along the axons overnight. The next day, glands and tracheae were removed from the ALs. To reduce movement, the esophagus was extended with forceps through a cut above the labium, and the abdomen was immobilized with a piece of sponge. The brain was covered by a thin layer of twocomponent silicone (KwikSil; World Precision Instruments). A plastic coverslip separated the antennae from the imaging area to keep them dry and accessible for odor stimulation. The temperature at the setup was set to $28^{\circ} \mathrm{C}$.

Odors and olfactometer. Odor stimuli generally consisted of 800-mslong square pulses of odorants. Synchronous mixtures were created by opening the valves of two odorants at the same time. Asynchronous mixtures were created by applying the odorant pulses with a time delay of different lengths, resulting in overlapping stimuli with either hexanol leading and nonanol trailing or vice versa. An overview of the stimuli used is provided in Figure 1. Linalool (CAS 78-70-6), 1-hexanol (CAS 111-27-3, 99.9\%), and 1-nonanol (CAS 143-08-8, 98\%) (SigmaAldrich) were diluted 1:100 in mineral oil (Sigma-Aldrich) and kept in glass vials with argon or nitrogen atmosphere to prevent oxidation. Next, $100 \mu \mathrm{l}$ of odor solution were placed on a cellulose pad (SugiPad; Kettenbach) in a $3 \mathrm{~mL}$ plastic syringe (NormJect; HSW) with the plunger set to $2.5 \mathrm{~mL}$. Syringes were placed in a custom-built four-channel olfactometer (Szyszka et al., 2011). Fresh odor syringes were used for every day of the experiments. Each odor channel was set to $300 \mathrm{~mL} / \mathrm{min}$ flow volume, which was injected into a carrier airstream of $1800 \mathrm{~mL} / \mathrm{min}$. The airspeed at the outlet was $1.4 \mathrm{~m} / \mathrm{s}$. Solenoids were selected in pairs to achieve onset accuracies of $1 \mathrm{~ms}$. Solenoid switch was controlled from a different computer than the one used for data acquisition. Stimulus control software was written in LabView 8.0 (National Instruments), allowing control pulse application with submicrosecond accuracy. The solenoid switch pulse consisted of a 1-ms-long $24 \mathrm{~V}$ pulse, followed by a $12 \mathrm{~V}$ hold for the time of the stimulus (spike and hold) using custom electronics. This circuitry allows for fast and temporally precise stimulus control. The olfactometer was placed $1 \mathrm{~cm}$ in front of the bees' antennae. We used two odor stimulation blocks. The first block consisted of the components, the synchronous mixture, and the 6-ms-asynchronous mixtures. The second block consisted of the solvent control, a diagnostic stimulus (linalool), followed by the stimuli from the first block, pseudorandomized with and completed by asynchronous mixtures with 50 and $200 \mathrm{~ms}$ delay. Because the first odor responses of an experiment are known to be highly variable (Stopfer and Laurent, 1999) and we only gave a subset of stimuli during the first block, we only analyzed the responses of the second experiment block.

Data acquisition and analyses. We recorded 203 glomeruli in 14 bees, an average of 14.5 glomeruli per bee, with an SD of 4.4 glomeruli per bee. Bees were imaged with an Olympus BX50WI microscope equipped with a XlumPlanFL $20 \times$, numerical aperture $0.95 \mathrm{~W}$ objective. Excitation light was set to $488 \mathrm{~nm}$. Emission was filtered with a GCamp filter set (495 dichroic mirror and 505 long-pass filter), recorded at $170^{\star} 128$ pixel $\left(437^{\star} 329 \mu \mathrm{m}\right)$ and 12 bit depth with an imaging system (IMAGO QE CCD Camera and Vision software; Till Photonics). Each measurement consisted of 200 frames measured at a frame rate of $20 \mathrm{~Hz}$, for a total length of $10 \mathrm{~s}$. Time between measurements was $60 \mathrm{~s}$. Raw data movies were processed with custom written programs in IDL (RSI) to execute offline movement correction, logarithmic bleaching correction and a mean time filtering with a kernel size of 3 . Signals were calculated as relative fluorescent changes $\frac{\Delta F}{F}$. For visualization in color-coded images, odor responses were also median filtered in space with a kernel size of 3 , and response strength was defined as the maximal signal change within $4 \mathrm{~s}$ after stimulus onset. Glomerular response traces were calculated within a square of $7^{\rtimes} 7$ pixel ( $\sim 18 \mu \mathrm{m}$ side length) placed on the individual glomeruli (Fig. $2 A$ ). We used an algorithm to segment glomeruli (Strauch et al., 2012, Fig. 2B) and identified a subset of them by means of their position using the honeybee AL standard atlas (Galizia et al., 1999). The constant pixel number allowed for a direct comparison of spontaneous activity (SD of the signal before stimulus onset) and response strength. Average response traces show the mean calculated between subjects.

Correlation analyses. Correlation matrices show the time-resolved similarity within (autocorrelation) and between (cross-correlation) odor response patterns (Fig. 5). Response patterns were represented as vectors consisting of the 203 glomeruli recorded in 14 bees. Every pixel in the matrix gives a Pearson's correlation coefficient of two response patterns during one time point (measured response frame). The diagonal represents the correlation of response patterns at the same time point. Pixelwise deviation from the diagonal shows the correlation of the two response patterns when shifted framewise. Correlation traces were extracted from the matrices for frame 64 (150 ms after stimulus onset) of the component response.

Principal component analysis. Principal components were calculated on the 203-dimensional hypervolume spanned by the analyzed glomeruli (Fig. 6). Principal component analysis (PCA) was performed with the "prcomp" function of the package "stats" in R (R Development Core Team, 2011). The transformation matrix was calculated on a time window within the initial $200 \mathrm{~ms}$ (frames 62-65) of the odor responses to the components, the synchronous mixture, and the 6-ms-asynchronous mixtures. We deemed this time window as relevant because neurons one or two synapses downstream of PNs respond within this time (Szyszka et al., 2005; Strube-Bloss et al., 2011, 2012). The 2D $m^{*} n$ loading matrix $L$ was calculated as:

$$
L_{i j}=\frac{\sum_{k=1}^{P} R_{i k} X_{k j}}{s_{j}^{2} \times d}
$$


A

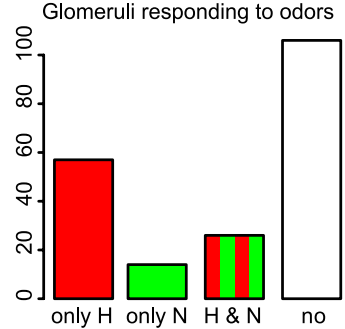

C

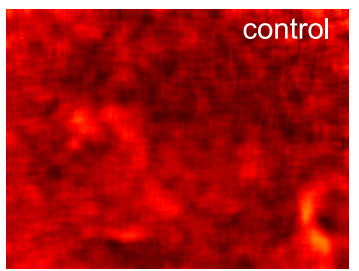

D
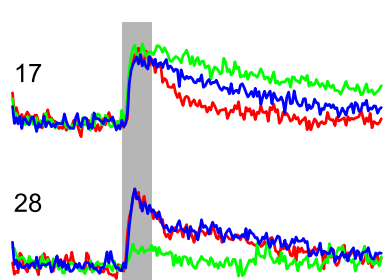

$\square \mathrm{H}$

$\square \mathrm{N}$

HN
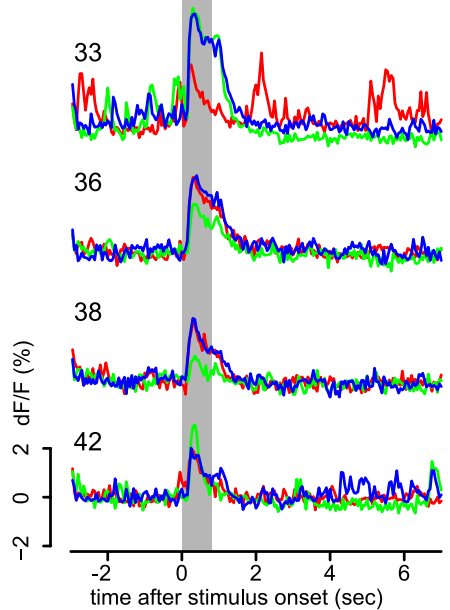

B
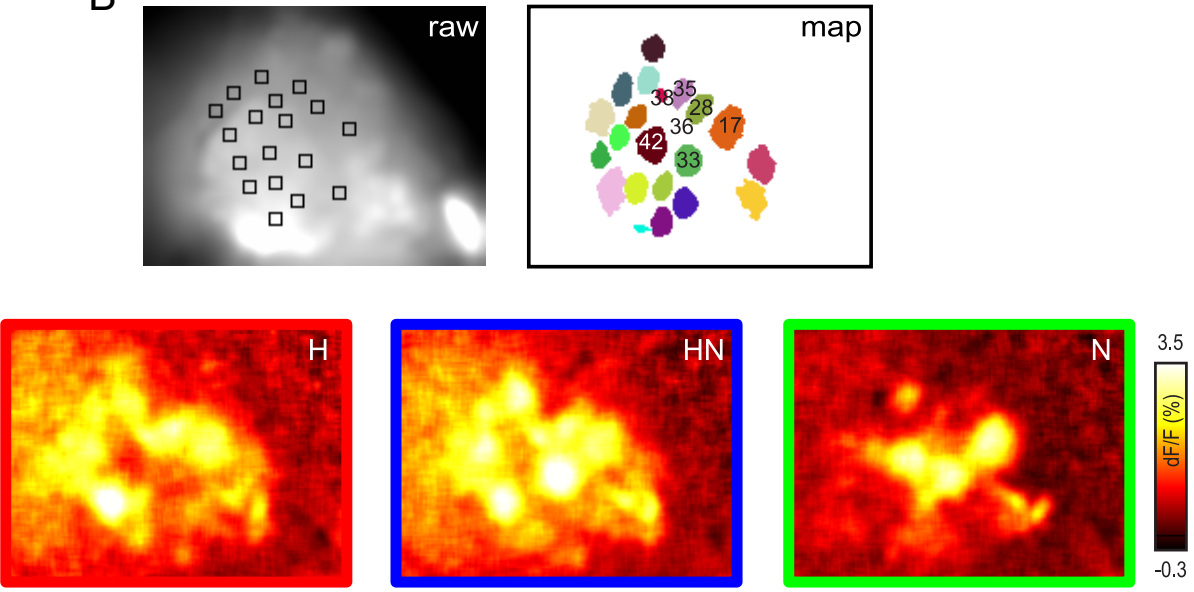

E

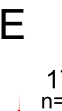

$\mathrm{H}$
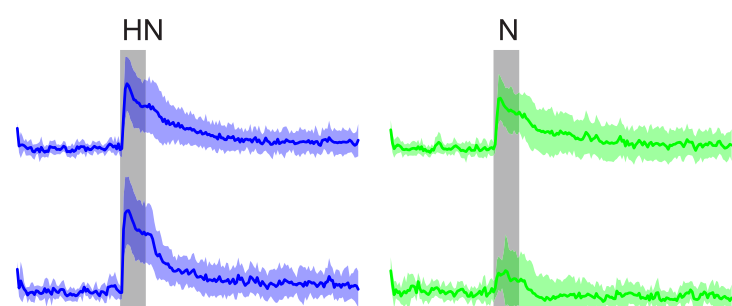

28

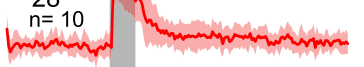

thaminin

$$
\mathrm{n}_{\mathrm{n}=6}
$$
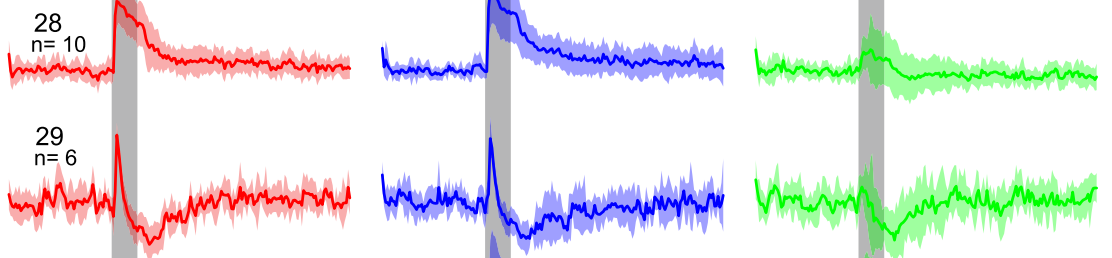

33
$n=11$
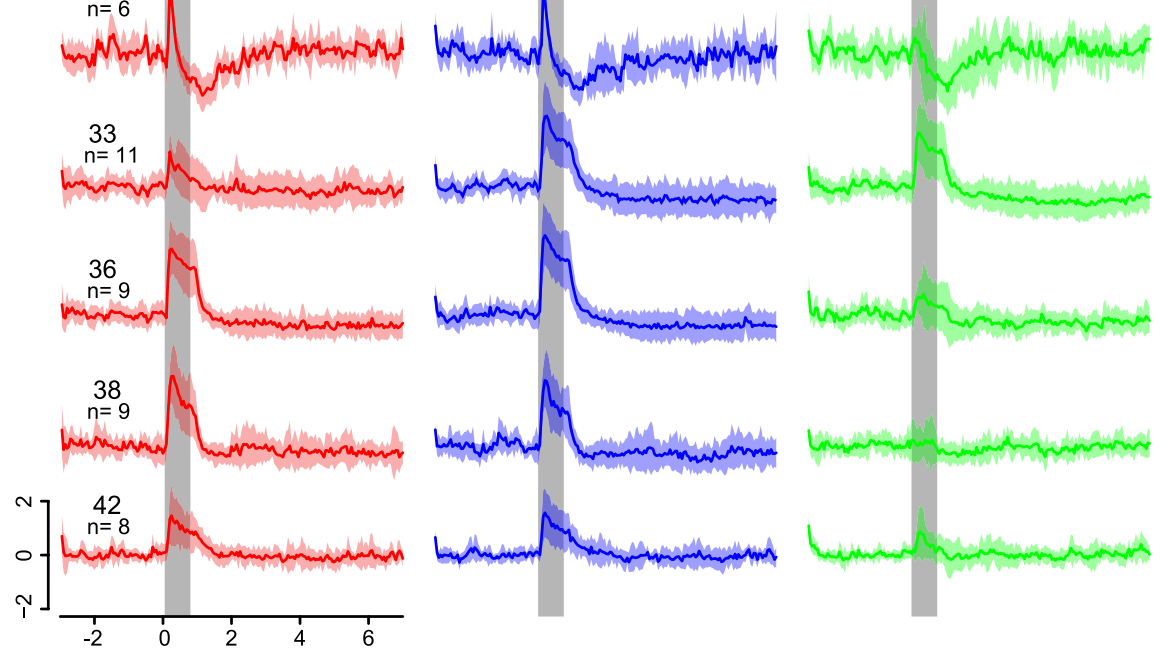

Figure 2. Calcium signal from responses to hexanol (H), nonanol (N), and the synchronous mixture (HN). $\boldsymbol{A}$, Number of glomeruli that responded either to $\mathrm{H}$ only, to $\mathrm{N}$ only, to both odors, or to neither of them. See Materials and Methods for the criteria after which a signal was considered as a response. $\boldsymbol{B}$, Left: Example of a raw fluorescence snapshot of an AL at $488 \mathrm{~nm}$ excitation. Squares indicate regions of interest from which traces were extracted. Right: Glomerular map attained from the data movies by the algorithm described in Strauch et al. (2012). $\boldsymbol{C}$, Color-coded images showing odor responses in an individual AL as relative calcium changes to mineral oil (control), the two components (H, N), and the synchronous mixture (HN). $\boldsymbol{D}$, Response time courses of six glomeruli from the same individual AL as in $\boldsymbol{B}$ and $\boldsymbol{C}$ to the components and the synchronous mixture. Numbers indicate the identity of T1 glomeruli as described by Galizia et al. (1999). $\boldsymbol{E}$, Response time courses of identified glomeruli averaged across animals. Traces show mean \pm SD. Gray bars indicate the odor stimulus. We did not identify glomerulus T1-29 in the specimen shown in $\boldsymbol{B}-\boldsymbol{D}$.

where $p=203$ is the number of glomeruli, which is the column number in the response matrix $R$ (the rows of $R$ contain the concatenated response traces: 1 frame per row, for a total of 1800 rows) to the different odor stimuli; $X$ is the transformation matrix from the PCA applied on the stimulus subset; $1 \leq i \leq m$ is the row index of $R$ and $L$ and $1 \leq j \leq n$ is the column index of $X$ and $L$; $s$ is a row vector containing the SDs of the principal components; and $d$ is an integer value giving the degree of freedoms.

Statistical analyses. A glomerulus calcium signal was considered as a response when the mean response during the $4 \mathrm{~s}$ after stimulus onset was at least 2.5 times greater than the noise level of that glomerulus. The noise level was defined as the SD of the signals before stimulus onset. Re- sponse strengths of the asynchronous mixtures were compared with the response strengths of the synchronous mixture using a repeatedmeasures ANOVA with a post hoc test (Holm-Sidak $\alpha$-value adjustment) with $\mathrm{R}$ and SigmaStat (Systat). The global significance level was set to $p=0.05$.

Additional experiments. A subset of experiments (17 bees) were performed (data from Fig. 4) with the following deviations in methods. We used 1-octanol (CAS 111-87-5) and 2-heptanone (CAS 110-43-0, both p. a. quality, Sigma) as odors, an olfactometer with six instead of four channels, Fura-2 (invitrogen) instead of Oregon Green, and acquired the data ratiometrically by taking double frames with excitation wavelength of 340 and $380 \mathrm{~nm}$. Excitation and emission light were separated with a 

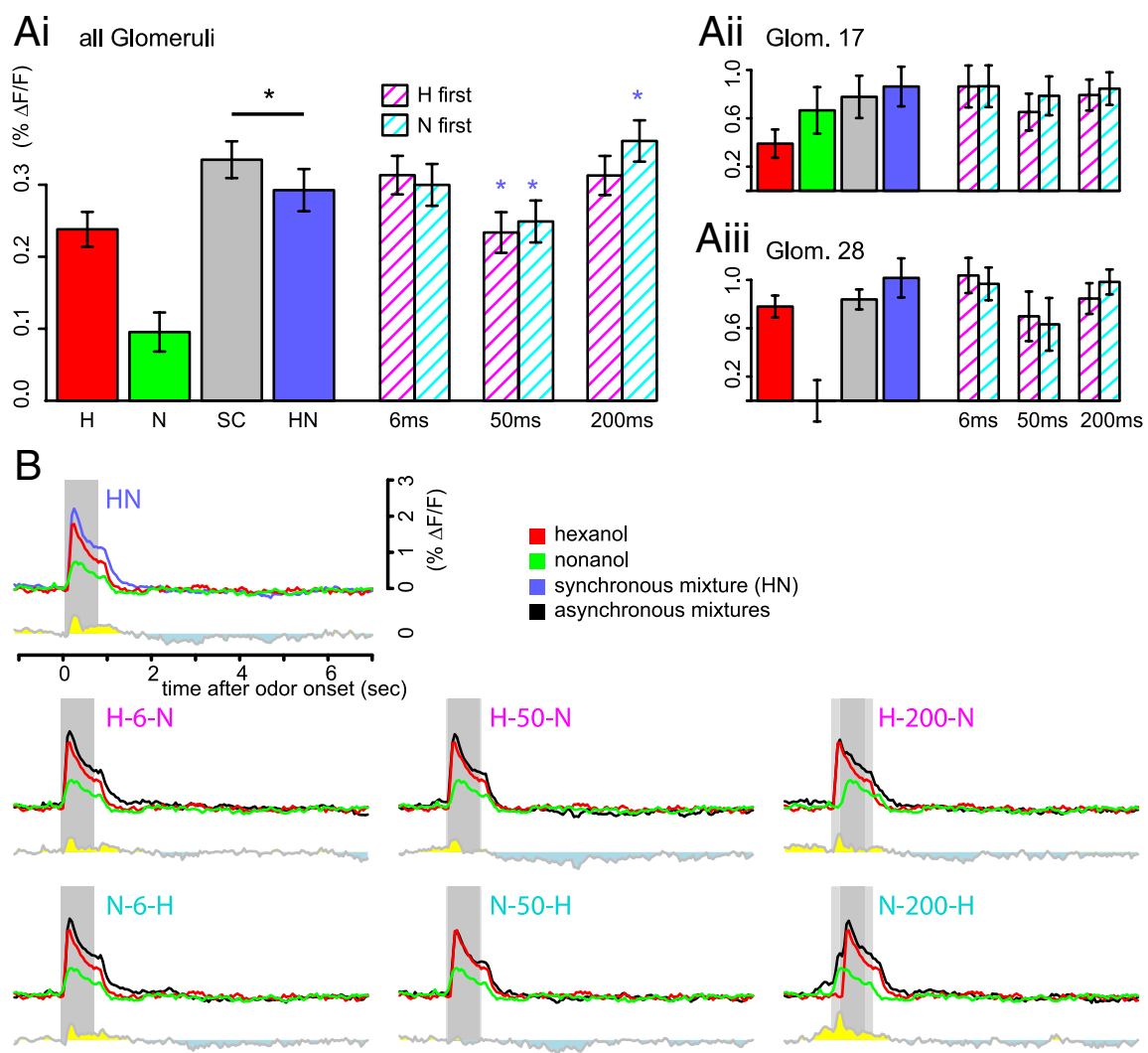

Figure 3. Asynchronous mixtures induce more inhibitory interactions than synchronous mixtures. Ai, Average PN response strengths during the $4 \mathrm{~s}$ after stimulus onset pooled over all measured glomeruli (bars show mean $\pm \mathrm{SEM}, n=203$ glomeruli, 14 bees). The gray bars show the average response strengths to the stronger component, which corresponds to the minimum expected response strength to the mixture in the absence of mixture interaction. Repeated-measures ANOVA revealed significant differences between mixtures $\left(F_{(6,202)}=7.43, p=7.8^{*} 10^{-8}\right)$. Blue asterisks denote significant differences from the synchronous mixture (Holm-Sidak post hoc test, global $p<0.05$ ). Aii, Same analysis as in $\mathbf{A i}$, performed over glomeruli T1-T17, $n=11$. Aiii, Same analysis as in $\boldsymbol{A i}$, performed over glomeruli T1-T28, $n=10$. $\boldsymbol{B}$, Average response traces of 203 glomeruli to the synchronous mixture (blue), the asynchronous mixtures (black), and their components hexanol (red) and octanol (green). Component traces were shifted according to their delay in the mixture. Bottom gray traces are the averaged, time-resolved difference between the mixture and the stronger component calculated on the level of subjects and then averaged. Times at which the response to the mixture is higher are marked yellow, times at which the response to the stronger component is higher are marked blue (indicating inhibitory mixture interaction).

$420 \mathrm{~nm}$ dichroic mirror and a 490-530 nm emission filter. The signal was calculated as $\Delta \frac{340}{380}$. Finally, the frame rate was $5 \mathrm{~Hz}$ instead of $20 \mathrm{~Hz}$.

\section{Results}

Odor and postodor responses are stimulus and glomerulus specific

We stimulated the antennae with hexanol $(\mathrm{H})$, nonanol $(\mathrm{N})$ and their synchronous and asynchronous mixtures (Fig. 1) and recorded calcium signals of the PNs in 203 glomeruli in 15 ALs of 14 animals. Fifty-seven glomeruli responded to $\mathrm{H}$ only and 14 glomeruli responded to $\mathrm{N}$ only. Twenty-six glomeruli responded to both components and 106 responded only weakly $(<2.5$ SDs) or did not respond (Fig. $2 A)$. The strongest excitatory responses to $\mathrm{H}$ were recorded in glomeruli 28, 36, and 38, whereas for $\mathrm{N}$, the strongest excitatory responses were recorded in glomeruli 17 and 33 (Fig. 2C-E). Time courses of responses were also both glomerulus and odor specific. For example, responses of glomerulus 17 exhibited a slow decay to stimulation with $\mathrm{N}$ and a faster decay to stimulation with $\mathrm{H}$. Responses of glomerulus 28 were strong to $\mathrm{H}$ with a weak excitatory postodor response and weak to $\mathrm{N}$ without a postodor response. Responses of glomerulus 29 consisted of a short excitatory phase, followed by a strong inhibition already during ongoing odor stimulation with both $\mathrm{H}$ and N. Furthermore, it showed the strongest spontaneous activity. Responses of glomerulus 33 to $\mathrm{N}$ were excitatory during stimulation, followed by a weak but persistent inhibitory period after the stimulus, which was absent when stimulated with $\mathrm{H}$. These odor and postodor responses were consistent across animals and correspond well with those described in previous studies (e.g., compare responses to $\mathrm{N}$ in Figure 5C in Szyszka et al., 2011).

\section{Inhibitory mixture interactions in synchronous mixtures}

Generally, glomeruli that responded to one component also responded to the synchronous mixture. In most glomeruli, the response pattern to a synchronous mixture resembled the response to the stronger component (Fig. 2D,E). Averaged over all glomeruli, however, the response to the mixture was weaker than the response to the stronger component (Fig. $3 A i)$. The average glomerular response to $\mathrm{H}$ was stronger than the response to $\mathrm{N}$. This partly reflected the fact that fewer glomeruli respond to $\mathrm{N}$ than to $\mathrm{H}$ (Fig. $2 A$ ). The average response to the synchronous mixture was lower than the response to the stronger component $(p=0.02$, paired Student's $t$ test). The mean value for the stronger component is higher than the mean value for $\mathrm{H}$ because in some glomeruli $\mathrm{N}$ was stronger than $\mathrm{H}$. The inhibitory mixture interaction for synchronous mixtures could not be related to specific identified glomeruli, indicating that the response strength of the entire $\mathrm{AL}$ was weaker than expected by the response of the individual components or that the inhibitory mixture interactions occurred in different glomeruli in different animals. The latter interpretation is consistent with the finding that the interglomerular inhibitory network is variable across animals (Girardin and Galizia, 2012).

\section{Temporal stimulus properties influence inhibitory interactions}

Mixture interactions are partly generated by a network of inhibitory neurons (Joerges et al., 1997; Silbering and Galizia, 2007; Deisig et al., 2010). We were interested in finding out if the processing of asynchronous mixtures elicits higher or lower activity in the inhibitory network than the processing of synchronous mixtures. Higher or lower inhibitory network activity would result in smaller or larger responses across all glomeruli, respectively. Indeed, the response strength was dependent on the mixture quality (Fig. 3Ai). We observed the strongest suppression at a delay of $50 \mathrm{~ms}$. The response strengths to asynchronous mixtures with 6 ms delay between the components did not differ from the synchronous mixture. When N preceded H with $200 \mathrm{~ms}$, the average response strength was significantly higher than to the 


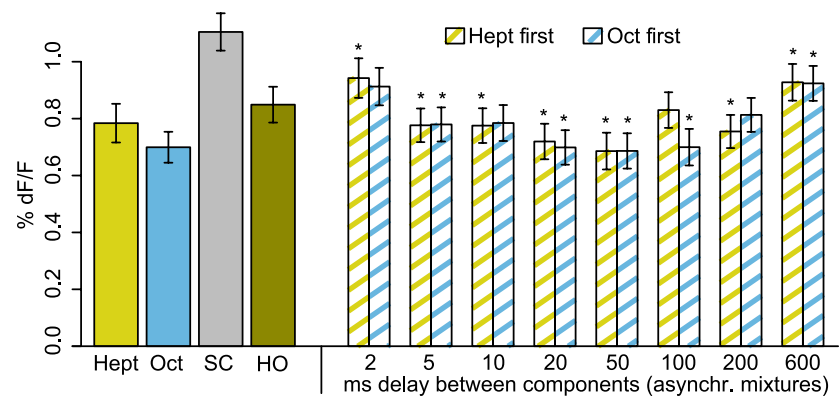

Figure 4. Inhibitory mixture interactions are strongest at $50 \mathrm{~ms}$ asynchrony. Average response strengths ( \pm SEM) of 171 glomeruli (different subjects as for $\mathrm{H}$ and $\mathrm{N}$ ) during $4 \mathrm{~s}$ after stimulus onset to 2-heptanone (Hept), 1-octanol (Oct), and the synchronous (HO) and asynchronous mixtures. The gray bar shows the average response strengths to the stronger component. Repeated-measures ANOVA revealed significant differences between mixtures $\left(F_{(16,170)}=13.172, p<10^{-15}\right)$. Asterisks denote significant difference of asynchronous mixtures to synchronous mixture. All mixtures were significantly lower than the stronger component (not indicated, Holm-Sidak post hoc test, global $p<0.05$, corrected for multiple testing).

synchronous mixture (Holm-Sidak post hoc test vs synchronous mixture, global significance level, $p=0.05$ ).

We were also interested in determining whether the additional asynchronous mixture interactions can be related to specific glomeruli. In many glomeruli, we found that with a delay of $50 \mathrm{~ms}$ between the components, the mixture response was lower than without delay or with a delay of 6 or 200 ms (e.g., in glomeruli 17 and 28; Fig. 3Aii,Aiii), but the effect with respect to identified glomeruli was not significant across animals. Moreover, a substantial part of the inhibition occurred in the postodor response, whereas during the stimulus, the response to the mixture was often stronger than or equal to the stronger component (Fig. 3B).

In the subset of experiments with 1-octanol and 2-heptanone and 9 different onset delays ranging from 0 to $600 \mathrm{~ms}$, we found similar results as in the main experiments. Again, the response strength was dependent on the timing of the components and we observed the strongest suppression at delays of $\sim 50 \mathrm{~ms}$ (Fig. 4). Responses of mixtures in which the octanol onset preceded the heptanone onset with 20 or $50 \mathrm{~ms}$ were significantly lower than the response to the synchronous mixture. Responses of mixtures in which the heptanone onset preceded the octanol onset were lower than the synchronous mixture for delays between 5 and 50 $\mathrm{ms}$ and $200 \mathrm{~ms}$ (Holm-Sidak post hoc test vs synchronous mixture, global significance level, $p=0.05$ ).

Because of the temporal complexity in many observed response traces, mixture interactions might occur in response parameters other than the mean response strengths. We therefore performed multivariate analyses to study mixture responses compared with the component responses on a global level, taking into account the spatiotemporal kinetics of odor responses.

\section{Synthetic and analytic information in synchronous and asynchronous mixture responses}

Honeybees recognize $\mathrm{H}$ and $\mathrm{N}$ better in an $6 \mathrm{~ms}$ asynchronous mixture than in a synchronous mixture of these two components (Szyszka et al., 2012). Therefore, the perception of an asynchronous mixture is more analytic and less synthetic than that of a synchronous mixture. Because the similarity of glomerular odor response pattern correlates well with perceived odor similarity (Guerrieri et al., 2005; Szyszka et al., 2011), we investigated whether this effect is also visible in the physiological responses of
PNs in the AL. If so, the representation of an asynchronous mixture should contain more information about its components than the synchronous mixture. We quantified the similarity between $\mathrm{PN}$ responses to components and synchronous and asynchronous mixtures. We performed time-resolved correlation analyses across all responses, in which the glomerular response pattern at any time frame of a stimulus was correlated to the pattern of every time frame of the same response (autocorrelation; Fig. 5B-E, left), and of the component responses as reference (Fig. 5B-E, center and right). Odor responses consisted of stable odor response phases (visible as boxes of high correlation diagrammed in Fig. 5Ai). Responses to $\mathrm{H}$ and $\mathrm{N}$ had a short transient phase that lasted about $200 \mathrm{~ms}$ and then a stable odor response that lasted as long as the stimulus, whereas the synchronous mixture lacked the transient phase. After stimulus offset, $\mathrm{PN}$ activity changed into a postodor response that was not correlated with the odor response, but that was relatively stable within itself (corresponding regions are diagrammed in Fig. 5Aiii). Both odor response patterns and postodor patterns were odor specific. Cross-correlation across odors was low $(0.23 \pm 0.12)$ and intermediate for odor component against the synchronous mixture (Table 1). The mixture response was more correlated to $\mathrm{H}$ than to $\mathrm{N}$, reflecting the larger number of glomeruli responding to $\mathrm{H}$ than to $\mathrm{N}$ (i.e., a larger overlap of responding glomeruli between $\mathrm{H}$ and the mixture). Interestingly, the correlation between the synchronous mixture and the initial $\mathrm{H}$ response was high only in the beginning of the stimulus and decayed fast, whereas the correlation with the initial $\mathrm{N}$ response was generally lower but persisted the entire stimulus and decayed slowly (Fig. 5B-E, traces).

The sequence of odors in a $6 \mathrm{~ms}$ asynchronous mixture plays a role for the similarity of the mixture with the components: When $\mathrm{H}$ was given $6 \mathrm{~ms}$ before $\mathrm{N}(\mathrm{H}-6-\mathrm{N})$, the correlation with $\mathrm{N}$ across all frames during the odor stimulation (diagrammed in Fig. 5Ai) was lower than in the synchronous mixture and in N-6-H. Moreover, the correlation with the components was higher in $\mathrm{N}-6-\mathrm{H}$ than in $\mathrm{H}-6-\mathrm{N}$ (Table 1 and compare traces and matrices between Fig. $5 B, C)$.

\section{Successive synthetic and analytic component representations in asynchronous mixtures}

When the delay between the two components was increased to 50 and $200 \mathrm{~ms}$, the overall correlation of the asynchronous mixtures (both sequences) to $\mathrm{H}$ was still stronger than the correlation to $\mathrm{N}$ (Fig. 5D,E, Table 1). Due to our sample interval of $50 \mathrm{~ms}$, the leading odor starts one measurement frame before the trailing odor for $50 \mathrm{~ms}$ onset (four frames for $200 \mathrm{~ms}$ onset shift). This resulted in high correlation values with the leading odor in the beginning of the stimulus. In addition to this trivial effect, we observed other, network-generated sequence effects. The correlation of $\mathrm{H}-50-\mathrm{N}$ and $\mathrm{N}$ was persistent from the onset of $\mathrm{N}$ until the end of the stimulus. The correlation of N-50-H and N (leading odor) collapsed when $\mathrm{H}$ (trailing odor) was added (Fig. $5 D$, arrowhead 1). However, the correlation of H-50-N and $\mathrm{H}$ (leading odor) did not collapse when $\mathrm{N}$ (trailing odor) was added. Therefore, the representation of $\mathrm{H}$ and $\mathrm{N}$ does not follow the same logic when given in changed sequence. A similar effect occurred at a delay of $200 \mathrm{~ms}$ (Fig. 5E). The addition of $\mathrm{H}$ in $\mathrm{N}-200-\mathrm{H}$ led to a collapse of the $\mathrm{N}$ representation (Fig. $5 E$, arrowhead 2), which later recovered, and to a strong correlation with $\mathrm{H}$, but not vice versa (Fig. 5E, arrowhead 3). The representation of the initial component response in the mixture $\mathrm{N}-200-\mathrm{H}$ changed several times during the stimulus (Fig. $5 E$, traces), suggesting a 
A

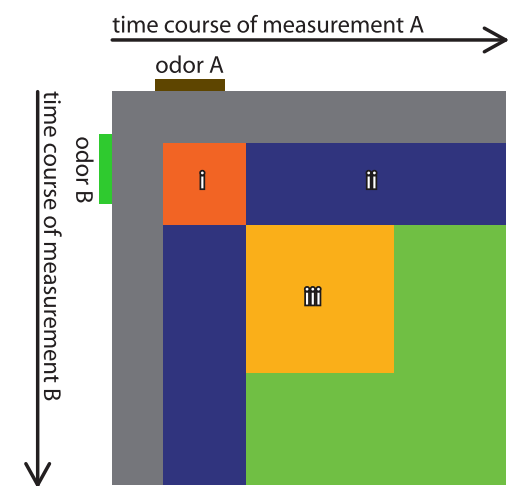

i: correlation of odor response $A$ with odor response $B$ ii: correlation of odor response $B$ with post-odor response $B$ iii: correlation of post-odor response $A$ with post-odor response $B$

B
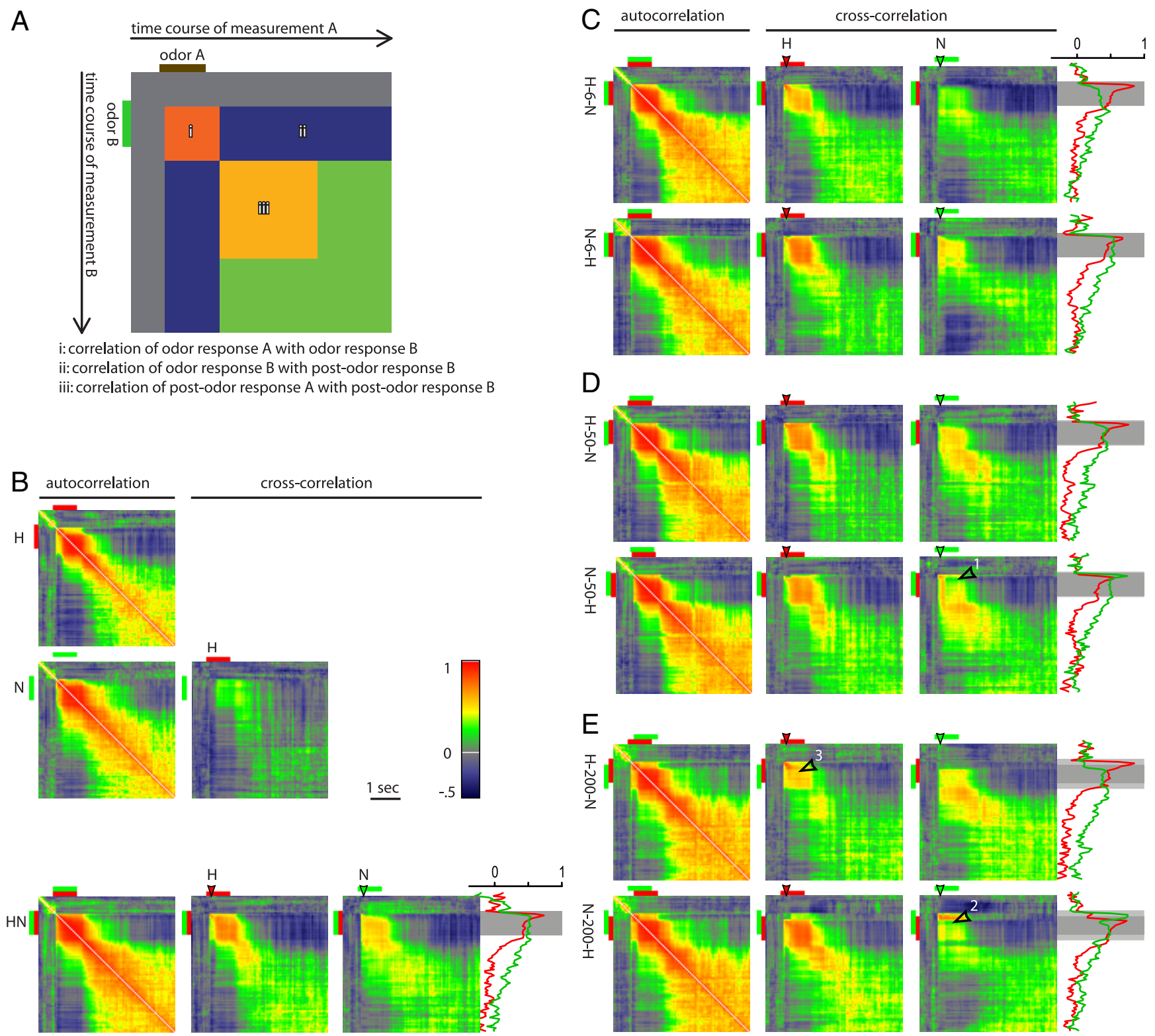

D
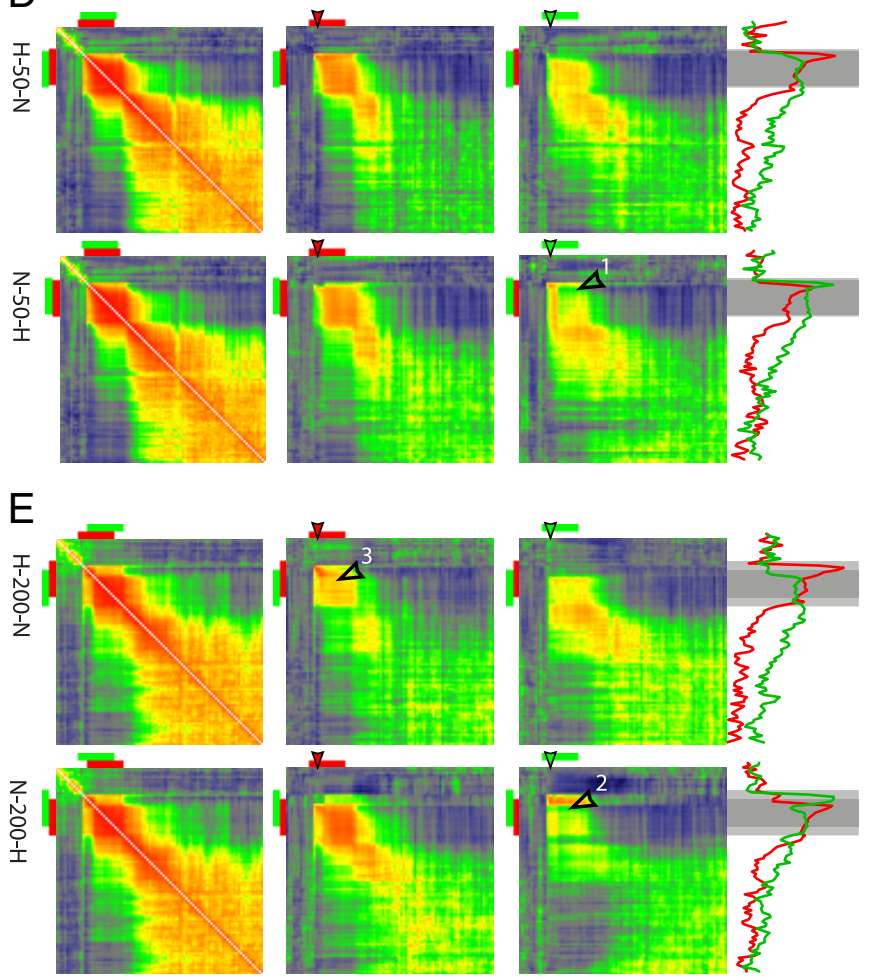

Figure 5. Cross-correlation matrices of glomerular response patterns of two stimuli. Every pixel gives a correlation value of two glomerular response patterns (vectors of length 203) for a certain time lag between two stimuli. $\boldsymbol{A}$, Schematic of the cross-correlation between an odor A and an odor B explaining the meaning of the components in each cross-correlation image. $\boldsymbol{B}$, Auto- and cross-correlation of the components and the synchronous mixture. N (green) indicates nonanol; $H$ (red), hexanol. Time traces of the correlation values in the vertical line indicated by the filled arrowheads are shown at the side. Red indicates the correlation between the initial hexanol response and the mixture response; green, correlation between the initial nonanol response and the mixture response. $\boldsymbol{C}-\boldsymbol{E}$, Autocorrelation and crosscorrelation of the components and the asynchronous mixtures. Numbered arrowheads refer to effects described in the text.

Table 1. Correlation coefficients between mixtures and components $\mathrm{H}$ and $\mathrm{N}$

\begin{tabular}{llllll}
\hline & \multicolumn{2}{l}{ Correlation with H } & & \multicolumn{2}{l}{ Correlation with N } \\
\cline { 2 - 3 } & Mean & SD & & Mean & SD \\
\hline HN & 0.63 & 0.11 & 0.50 & 0.09 \\
H-6-N & 0.56 & 0.09 & 0.30 & 0.12 \\
N-6-H & 0.64 & 0.12 & 0.46 & 0.10 \\
H-50-N & 0.64 & 0.11 & 0.46 & 0.11 \\
N-50-H & 0.55 & 0.16 & 0.44 & 0.10 \\
H-200-N & 0.53 & 0.08 & 0.33 & 0.16 \\
N-200-H & 0.59 & 0.20 & 0.43 & 0.13 \\
\hline
\end{tabular}

Data are averaged (mean) values and SDs of the cross-correlation analyses shown in Figure 5 during the $0.1-0.9 \mathrm{~s}$ after stimulus onset.

successive and analytic representation of the stimulus rather than a synthetic representation. After $\mathrm{N}$ offset, the correlation of the response with the $\mathrm{N}$ response decreased again, but recovered after $\mathrm{H}$ was set off as well.
These manifold changes were also evident in the autocorrelation patterns, which exhibited four phases with a stable, high correlation within themselves but different from each other: The first phase corresponded to the representation of the leading odor, the second phase corresponded to the mixture response, the third phase corresponded to the trailing odor, and the fourth phase was the postodor response.

The correlation between the asynchronous mixture and the components was high when an odor was added to the mixture and when it was present alone in beginning and end of the stimulus. Further, the correlation with the leading odor decreased temporarily when the new odor was added, but recovered shortly after. Therefore, these stimuli created temporally complex responses (i.e., the glomerular response pattern changed from one odor identity to another). Finally, against component and asyn- 

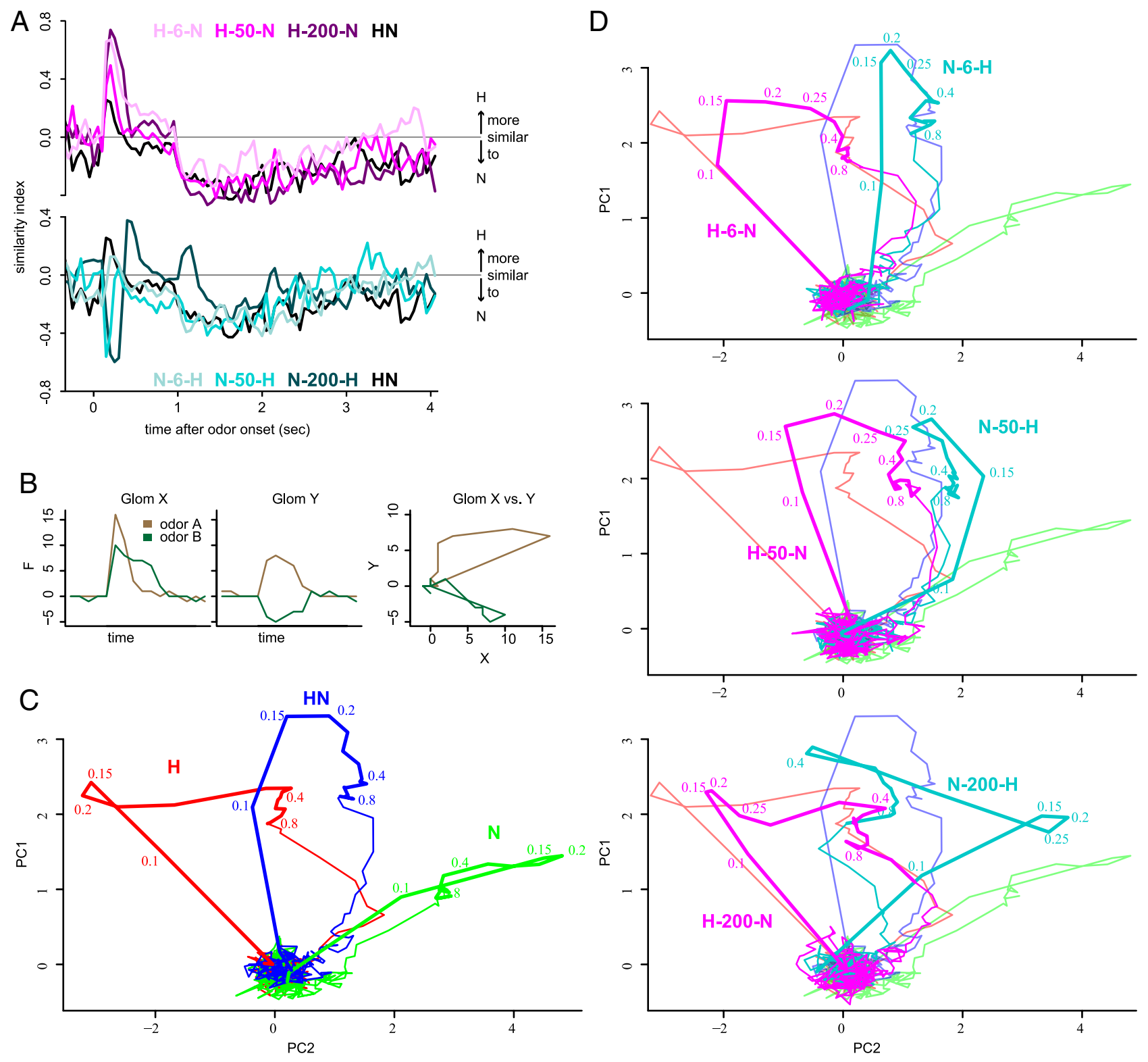

Figure 6. The leading odor becomes more prominent in asynchronous mixtures. A, The similarity index, correlation $[H$ vs mix $]$ - correlation $[N$ vs mix] for synchronous and asynchronous mixtures. Positive values indicate a higher correlation between $\mathrm{H}$ and a mixture; negative values indicate higher correlation between $\mathrm{N}$ and a mixture. Top: Similarity index for the synchronous mixture $\mathrm{HN}$ and for asynchronous mixtures that start with H. Bottom: Similarity index for HN and for asynchronous mixtures that start with N. The initial responses of asynchronous mixtures were more similar to the leading odor than to the trailing odor (same data as traces in Fig. 5). B, Principle of trajectory calculation for two glomeruli (fictive response time courses). C, D, Trajectories of the responses from 203 glomeruli for the components and the synchronous mixture $(C$ and for asynchronous mixtures with $6 \mathrm{~ms}$ (top), $50 \mathrm{~ms}$ (middle) und $200 \mathrm{~ms}$ (bottom), each with hexanol first (magenta) and nonanol first (cyan) (D). Plots contain the trajectories from C for comparison. Numbers next to trajectories indicate the time after stimulus onset in seconds. PC1 and PC2 explain $80 \%$ of the variance.

chronous mixture responses, the responses to the synchronous mixture were less temporally complex, comprising only one stable odor response pattern and the postodor response.

\section{The leading component dominates the odor response to asynchronous mixtures}

The correlation analysis showed that synchronous and asynchronous responses were generally more similar to the $\mathrm{H}$ pattern than to the $\mathrm{N}$ pattern (Fig. 5). To determine whether stimulus asynchrony changes the component-to-mixture similarity, we calculated a similarity index as the difference between the $\mathrm{H}$-tomixture correlation and the N-to-mixture correlation (Fig. 6A). The initial responses to asynchronous mixtures were more similar to the leading odors than to the trailing odors, and the re- sponses to leading odors were more similar to the responses to asynchronous mixtures than to synchronous mixtures.

Although pairwise correlation analyses can describe the absolute similarity of one odor response with one certain reference trace with precise temporal resolution, it cannot display the evolution of a response pattern relative to all other stimuli at the same time. By means of PCA, we overcame these limitations and projected the multidimensional responses as trajectories into a 2D space (exemplified for two glomeruli in Fig. $6 B$ ) chosen to display the highest possible amount of variance: the first two principal components. The trajectories of the two components $\mathrm{H}$ and $\mathrm{N}$ were clearly separated in this plane (PC1 and PC2; Fig. 6C). The synchronous mixture trajectory evolved between the components. Odor responses reached their biggest separation $0.2 \mathrm{~s}$ 
after stimulus onset and reached a steady state after $0.5 \mathrm{~s}$, after which only minor changes in the pattern occurred until odor offset. Trajectories of the asynchronous mixtures deviated from the synchronous mixture toward the leading odor component (Fig. 6D). After the initial deviation, trajectories moved toward the synchronous mixture (or, at a delay of $200 \mathrm{~ms}$, toward the trailing odor). Generally, the longer the delay, the more often the trajectory changed its direction. Asynchronous mixtures with a $200 \mathrm{~ms}$ delay initially followed the leading odor. After onset of the trailing odor, they turned into its direction before they reached a steady state in the synchronous mixture area. This effect was most distinct at a delay of $200 \mathrm{~ms}$. The trajectory of the asynchronous mixture $\mathrm{N}-200-\mathrm{H}$ headed to the direction of $\mathrm{H}$ twice: first, after $\mathrm{H}$ was added to the mixture and at the end of the stimulus, when $\mathrm{N}$ was set off but $\mathrm{H}$ remained on. Similarly, the trajectory of $\mathrm{H}-200-\mathrm{N}$ headed to $\mathrm{N}$ in the end of the stimulation. Therefore, in asynchronous mixtures with long delays between the components, there are time windows in which the glomerular activation pattern deviates from the mixture patterns in favor of the components. The evolution of the responses to asynchronous mixtures is biased toward the leading odors, with 200 ms generating the most distinct deviation. Moreover, the processing of the mixtures tended to be shifted from a synthetic toward an analytic fashion.

\section{Discussion}

In the wild, insects experience both synchronous odorant mixtures (e.g., the bouquet of a flower odor, which consists of many chemicals) and asynchronous mixtures (e.g., when the odor of two flowers mix in the turbulent air). Here we analyzed how synchronous and asynchronous mixtures are processed in the honeybee AL and show that PNs are sensitive to millisecond asynchrony between the components of asynchronous mixtures.

\section{Asynchronous mixtures contain information about their components}

We found that in PNs, synchronous mixtures elicit odor responses that are similar to the component responses, but reduced in strength due to inhibitory interactions, confirming previously published observations in insects (Joerges et al., 1997; Galizia et al., 2000; Silbering and Galizia, 2007; Deisig et al., 2010; NajarRodriguez et al., 2010) and vertebrates (Tabor et al., 2004; Grossman et al., 2008). However, when mixtures were asynchronous, inhibitory interactions increased. Most importantly, we found that even an onset delay of 6 ms was sufficient to generate a response pattern that was initially biased toward the leading odor. With increasing odor onset delays (50, $200 \mathrm{~ms}$ ), the AL showed an increasingly analytic processing mode in that leading odor, mixture, and trailing odor were represented successively. Accordingly, the total amount of inhibitory interactions was not increased any more with time delays of $200 \mathrm{~ms}$. Local neurons in the AL might favor different coding strategies (analytic or synthetic), depending on the stimulus timing (Meyer and Galizia, 2012). The increased inhibitory interactions that occurred between 5 and 100 ms suggests a timing-dependent inhibitory network that is activated only during a distinct time window after an odor onset-a winner-takes-all network that changes the response to odor mixtures if asynchrony is detected (Nowotny et al., 2012). Whether this timing-dependent inhibitory network plays a role in enhancing the separability between two components in asynchronous mixtures remains to be determined.

Small odor onset time delays of $6 \mathrm{~ms}$ help honeybees to segregate odor components from mixtures (Szyszka et al., 2012). In the moth pheromone system, time differences of as little as $1 \mathrm{~ms}$ between the pheromone and an antagonist were sufficient for the animals to judge the mixture as not being a perfect blend, rendering the antagonistic effect less efficient (Baker et al., 1998). Together, the previous behavioral data and our physiological data presented here show that olfactory processing in insects is fast, although they do not indicate how fast. Indeed, the fact that we could see the 6 ms delay in measurements with a sampling interval of $50 \mathrm{~ms}$ indicates that fast effects in the periphery might have physiological effects at a slower timescale in the brain.

Nikonov and Leal (2002) reported mixture suppression of olfactory receptor neurons (ORNs) compartmentalized in the same sensillum, which occurred only when both components were delivered synchronously. This supports the idea of on-site coincident detectors realized by sensilla housing ORNs of different tunings. Moreover, lateral inhibition of neighboring ORNs has been described previously (Hillier and Vickers, 2011; Su et al., 2012). In honeybees, ORNs are mainly located in sensilla placodea. These sensilla contain up to $30 \mathrm{ORNs}$ that innervate the AL with highly diverse glomerular patterns (Kelber et al., 2006), thus maximizing the chance that two arbitrary odors may activate two ORNs within the same sensillum. The ORNs that respond to the leading odor could suppress the ORN responses to the trailing odor in the same sensillum. Such a mechanism could explain both the increased inhibitory interaction and the dominance of a leading odor in asynchronous mixtures. These studies give rise to the hypothesis that already within a single sensillum, the processing of one odor might be affected by the presence and the timing of another odor.

Compared with behavioral data in honeybees (Szyszka et al., 2012), our data show one discrepancy: while with $6 \mathrm{~ms}$ time shift we see the identity of the leading odor in the AL pattern, the identity of the trailing odor remains masked, even though the behavioral effect was almost symmetrical. We conclude that either the temporal resolution of the calciumsensitive dye or of the intracellular calcium concentration was not sufficient (both have fast time constants for calcium increases, but slower ones for calcium decreases), or the identity of the leading and the trailing odor might be extracted by other regions of the bee brain. For example, this could be the mushroom bodies (MBs), the Kenyon cells of which code odor information in a highly synthetic fashion (Laurent, 2002; Perez-Orive et al., 2002; Szyszka et al., 2005; Jortner et al., 2007): Odors that activate overlapping sets of PNs in the AL activate distinct sets of Kenyon cells in the MBs. Moreover, Kenyon cells are particularly sensitive to synchronous input and respond mainly to odor onset. Therefore, the leading and trailing component in an asynchronous mixture might activate different Kenyon cell ensembles that resemble the single components rather than the synchronous mixture. These hypotheses remain to be tested, for example, by measurements with higher sampling rates and by recording Kenyon cells in the MBs.

Are there further aspects in the activity patterns that would help the animal differentiate between a synchronous and an asynchronous mixture? For example, components may be processed sequentially, as has been shown previously for humans (Laing et al., 1994; Jinks and Laing, 1999). The multiphasic odor response patterns that we observed for 50 and 200 ms delays would argue in favor of such a view. Unlike the fairly stable "plateau" responses of the synchronous mixtures, these patterns had a temporal complexity that by itself could be used by the brain to extract information about the stimulus quality. 


\section{Odor dominance effects}

In our recordings, $\mathrm{H}$ was generally dominant over $\mathrm{N}$ (i.e., mixtures were generally more similar to $\mathrm{H}$ than to $\mathrm{N}$. We took great care to develop a perfectly symmetrical olfactometer (Szyszka et al., 2012), so we can exclude the possibility that the time difference may have been unequal. Therefore, it is possible that odors differ in their dominance within the AL network (e.g., due to a stronger connection to the inhibitory network based either on innate or on acquired properties). However, in our case it could also be a consequence of the fact that $\mathrm{H}$ elicited activity in more glomeruli than $\mathrm{N}$ (Fig. 2A), which results in $\mathrm{H}$ having a stronger weight both in the correlation analyses and in the PCA analysis. Because we could only sample a subpopulation of glomeruli in the AL, it might be that if recorded across all 160 glomeruli, odors would become more symmetrical. However, this observation might also reflect another effect: odors that activate many glomeruli (i.e., for which there are many responsive olfactory receptors) might have a net advantage on other odors in their processing dominance in the AL.

\section{Odor object segregation}

Previous studies showed that mammals can use stimulus asynchrony for odor-background segregation, although on a slower timescale: several seconds versus milliseconds in insects (Kadohisa and Wilson, 2006; Linster et al., 2007). The principle that onset asynchrony between stimuli can be used to enhance separability, and thus prevent the creation of concurrent stimuli as a unitary percept (object or "gestalt"), has been studied in other modalities, including vision, audition, and tactile senses, and provides a basic principle for object recognition (Bronkhorst, 2000; Hancock et al., 2008; Gallace and Spence, 2011; Pressnitzer et al., 2011; Wagemans et al., 2012). These studies have shown that the synchrony of a stimulus can be used by the brain to "bind" its components, whereas asynchrony helps to segregate concurrent stimuli and thus enables the creation and segregation of objects. Our data show that this concept may also apply to the olfactory system. Binding the activity of different glomeruli in the response pattern of a synchronous mixture may be the substrate for creating the "perfume" percept, the experience of an odor in which the unique identity of the mixture obliterates the information of the mixture components. In other words: temporal asynchrony between two components in a stimulus may inhibit the binding and result in segregation. That is, the information of the components is preserved in the odor response (two objects), whereas stimulus synchrony leads to binding in which the processing of the mixture renders a new odor quality (one object). We found more inhibition in responses to asynchronous mixtures (segregation of components) than to synchronous mixtures (binding of components). Therefore, the mere strength of inhibition in the glomerular responses might be not correlated with the degree of creating new odor qualities, which is inconsistent with previous results (Silbering and Galizia, 2007; Deisig et al., 2010). Instead, it could reflect the activity in inhibitory local neurons that are involved in creating spike synchrony across $\mathrm{PN}$ ensembles, which has been suggested to be important for odor processing (Perez-Orive et al., 2004; Giridhar et al., 2011). Further, the MBs are ideally suited to extract this synchrony (Laurent, 2002; Szyszka et al., 2005; Turner et al., 2008).

\section{References}

Baker TC, Fadamiro HY, Cosse AA (1998) Moth uses fine tuning for odour resolution [letter]. Nature 393:530. CrossRef

Bronkhorst AW (2000) The cocktail party phenomenon: a review of re- search on speech intelligibility in multiple-talker conditions. Acta Acustica united with Acustica 86:117-128.

Broome BM, Jayaraman V, Laurent G (2006) Encoding and decoding of overlapping odor sequences. Neuron 51:467-482. CrossRef Medline

Chandra, S. and Smith, B. H. (1998) An analysis of synthetic processing of odor mixtures in the honeybee (Apis mellifera). J Exp Biol 201(Pt 22): 3113-3121. Medline

Coureaud G, Hamdani Y, Schaal B, Thomas-Danguin T (2009) Elemental and configural processing of odour mixtures in the newborn rabbit. J Exp Biol 212:2525-2531. Medline

Deisig N, Giurfa M, Lachnit H, Sandoz, JC (2006) Neural representation of olfactory mixtures in the honeybee antennal lobe. Eur J Neurosci 24: 1161-1174. CrossRef Medline

Deisig N, Giurfa M, Sandoz JC (2010) Antennal lobe processing increases separability of odor mixture representations in the honeybee. J Neurophysiol 103:2185-2194. CrossRef Medline

Deisig, N., Lachnit, H., and Giurfa, M. (2002) The effect of similarity between elemental stimuli and compounds in olfactory patterning discriminations: learning and memory (pp 112-121). Cold Spring Harbor, NY: Cold Spring Harbor.

Galizia CG, McIlwrath SL, Menzel R (1999) A digital three-dimensional atlas of the honeybee antennal lobe based on optical sections acquired by confocal microscopy. Cell Tissue Res 295:383-394. CrossRef Medline

Galizia CG, Küttner A, Joerges J, Menzel R (2000) Odour representation in honeybee olfactory glomeruli shows slow temporal dynamics: an optical recording study using a voltage-sensitive dye. J Insect Physiol 46:877-886. CrossRef Medline

Gallace A, Spence C (2011) To what extent do Gestalt grouping principles influence tactile perception? Psychol Bull 137:538-561. CrossRef Medline

Girardin CC, Galizia CG (2012) The "where" and "who" in brain science: probing brain networks with local perturbations. Cognitive Computation 4:63-70. CrossRef

Giridhar S, Doiron B, Urban NN (2011) Timescale-dependent shaping of correlation by olfactory bulb lateral inhibition. Proc Natl Acad Sci U S A, 108:5843-5848. CrossRef Medline

Grossman KJ, Mallik AK, Ross J, Kay LM, Issa NP (2008) Glomerular activation patterns and the perception of odor mixtures. Eur J Neurosci 27: 2676-2685. CrossRef Medline

Guerrieri F, Schubert M, Sandoz, JC, Giurfa M (2005) Perceptual and neural olfactory similarity in honeybees. PLoS Biol 3:e60. CrossRef Medline

Hancock PJ, Walton L, Mitchell G, Plenderleith Y, Phillips WA (2008) Segregation by onset asynchrony. J Vis 8:21.1-21. CrossRef Medline

Hillier NK, Vickers NJ (2011) Mixture interactions in moth olfactory physiology: examining the effects of odorant mixture, concentration, distal stimulation, and antennal nerve transection on sensillar responses. Chem Senses 36:93-108. CrossRef

Hopfield JF, Gelperin A (1989) Differential conditioning to a compound stimulus and its components in the terrestrial mollusc Limax maximus. Behav Neurosci 103:329-333. CrossRef

Hopfield JJ (1991) Olfactory computation and object perception. Proc Natl Acad Sci U S A, 88:6462-6466. CrossRef Medline

Jinks A, Laing DG (1999) Temporal processing reveals a mechanism for limiting the capacity of humans to analyze odor mixtures. Brain Res Cogn Brain Res 8:311-325. CrossRef Medline

Joerges J, Küttner A, Galizia CG, Menzel R (1997) Representations of odours and odour mixtures visualized in the honeybee brain. Nature 387:285-288. CrossRef

Jortner RA, Farivar SS, Laurent G (2007) A simple connectivity scheme for sparse coding in an olfactory system. J Neurosci 27:1659-1669. CrossRef Medline

Kadohisa M, Wilson DA (2006) Olfactory cortical adaptation facilitates detection of odors against background. J Neurophysiol 95:1888-1896. CrossRef Medline

Kelber C, Rössler W, Kleineidam CJ (2006) Multiple olfactory receptor neurons and their axonal projections in the antennal lobe of the honeybee Apis mellifera. J Comp Neurol 496:395-405. CrossRef Medline

Laing DG, Eddy A, Francis GW, Stephens L (1994) Evidence for the temporal processing of odor mixtures in humans. Brain Res 651:317-328. CrossRef Medline

Laurent G (2002) Olfactory network dynamics and the coding of multidimensional signals. Nat Rev Neurosci 3:884-895. CrossRef Medline

Linster C, Henry L, Kadohisa M, Wilson DA (2007) Synaptic adaptation 
and odor-background segmentation. Neurobiol Learn Mem 87:352-360. CrossRef

Lipp R, Kitterick P, Summerfield Q, Bailey PJ, Paul-Jordanov I (2010) Concurrent sound segregation based on inharmonicity and onset asynchrony. Neuropsychologia 48:1417-1425. CrossRef Medline

Meyer A, Galizia CG (2012) Elemental and configural olfactory coding by antennal lobe neurons of the honeybee (Apis mellifera). J Comp Physiol A 198:159-171. CrossRef Medline

Najar-Rodriguez AJ, Galizia CG, Stierle J, Dorn S (2010) Behavioral and neurophysiological responses of an insect to changing ratios of constituents in host plant-derived volatile mixtures. J Exp Biol 213:3388-3397. CrossRef Medline

Nikonov AA, Leal WS (2002) Peripheral coding of sex pheromone and a behavioral antagonist in the Japanese beetle, Popillia japonica. J Chem Ecol 28:1075-1089. CrossRef Medline

Nowotny T, Galizia CG, Szyszka P (2012) Coding of temporally incoherent odour mixtures in the antennal lobe of honeybees. In: Neural Coding 2012: 10th International Workshop Book of Abstracts, p. 87. Czech Republic: Institute of Physiology Academy of Sciences of the Czech Republic.

Perez-Orive J, Mazor O, Turner GC, Cassenaer S, Wilson RI, Laurent G (2002) Oscillations and sparsening of odor representations in the mushroom body. Science 297:359-365. CrossRef Medline

Perez-Orive J, Bazhenov M, Laurent G (2004) Intrinsic and circuit properties favor coincidence detection for decoding oscillatory input. J Neurosci 24:6037-6047. CrossRef Medline

Pressnitzer D, Suied C, Shamma SA (2011) Auditory scene analysis: the sweet music of ambiguity. Front Hum Neurosci 5:158. CrossRef Medline

R Development Core Team (2011) R: a language and environment for statistical computing. Vienna: R Foundation for Statistical Computing.

Riffell JA, Abrell L, Hildebrand JG (2008) Physical processes and real-time chemical measurement of the insect olfactory environment. J Chem Ecol 34:837-853. CrossRef Medline

Silbering AF, Galizia CG (2007) Processing of odor mixtures in the Drosophila antennal lobe reveals both global inhibition and glomerulus-specific interactions. J Neurosci 27:11966-11977. CrossRef Medline

Silbering AF, Okada R, Ito K, Galizia CG (2008) Olfactory information processing in the Drosophila antennal lobe: anything goes? J Neurosci 28: 13075-13087. CrossRef Medline

Smith BH (1998) Analysis of interaction in binary odorant mixtures. Physiol Behav 65:397-407. CrossRef Medline
Stevenson RJ, Wilson DA (2007) Odour perception: an object-recognition approach. Perception 36:1821-1833. CrossRef Medline

Stopfer M, Laurent G (1999) Short-term memory in olfactory network dynamics. Nature 402:664-668. CrossRef Medline

Strauch M, Rein J, Giovanni Galizia C (2012) Signal extraction from movies of honeybee brain activity by convex analysis. In: 2012 IEEE 2 nd International Conference on Computational Advances in Bio and Medical Sciences, pp. 1-6. New York: IEEE.

Strube-Bloss MF, Nawrot MP, Menzel R (2011) Mushroom body output neurons encode odor-reward associations. J Neurosci 31:3129-3140. CrossRef Medline

Strube-Bloss MF, Herrera-Valdez MA, Smith BH (2012) Ensemble response in mushroom body output neurons of the honey bee outpaces spatiotemporal odor processing two synapses earlier in the antennal lobe. PLoS One 7:e50322. CrossRef Medline

Su C-Y, Menuz K, Reisert J, Carlson JR (2012) Non-synaptic inhibition between grouped neurons in an olfactory circuit. Nature 1-7.

Szyszka P, Ditzen M, Galkin A, Galizia CG, Menzel R (2005) Sparsening and temporal sharpening of olfactory representations in the honeybee mushroom bodies. J Neurophysiol 94:3303-3313. CrossRef Medline

Szyszka P, Demmler C, Oemisch M, Sommer L, Biergans S, Birnbach B, Silbering AF, Galizia CG (2011) Mind the gap: olfactory trace conditioning in honeybees. J Neurosci 31:7229-7239. CrossRef Medline

Szyszka P, Stierle JS, Biergans S, Galizia CG (2012) The Speed of Smell: Odor-Object Segregation within Milliseconds. PLoS One 7:e36096. CrossRef Medline

Tabor R, Yaksi E, Weislogel JM, Friedrich RW (2004) Processing of odor mixtures in the zebrafish olfactory bulb. J Neurosci 24:6611-6620. CrossRef Medline

Turner GC, Bazhenov M, Laurent G (2008) Olfactory representations by Drosophila mushroom body neurons. J Neurophysiol 99:734-746. CrossRef Medline

Usher M, Donnelly N (1998) Visual synchrony affects binding and segmentation in perception. Nature 394:179-182. CrossRef Medline

Wagemans J, Elder JH, Kubovy M, Palmer SE, Peterson MA, Singh M, von der Heydt R (2012) A century of Gestalt psychology in visual perception: I. Perceptual grouping and figure-ground organization. Psychol Bull 138:1172-1217. CrossRef Medline

Zera J, Green DM (1993) Detecting temporal onset and offset asynchrony in multicomponent complexes. J Acoust Am 93:1038-1052. CrossRef Medline 